\title{
What Strategy for a Severe Stroke in Africa: Palliative Care or Unreasonable Obstinacy?
}

\author{
Paul Macaire Ossou-Nguiet ${ }^{1,2 *}$, Ghislain Armel Mpandzou, ${ }^{1,2}$, Dinah Happhia Motoula Latou ${ }^{1,2}$, \\ Josué Euberma Diatewa1,2, Karen Lise Charmel Obondzo Aloba², \\ Prince Eliot Sounga Bandzouzi1,3, Bertrand Fikahem Ellenga Mbolla1
}

${ }^{1}$ Faculty of Health Sciences of Brazzaville, Brazzaville, Congo

${ }^{2}$ Department of Neurology, Brazzaville University Hospital, Brazzaville, Congo

${ }^{3}$ Department of Neurology, General Hospital of Loandjili, Pointe Noire, Congo

Email: *ossoupm@gmail.com

How to cite this paper: Ossou-Nguiet, P.M., Mpandzou, G.A., Motoula Latou, D.H., Diatewa, J.E., Obondzo Aloba, K.L.C., Sounga Bandzouzi, P.E. and Ellenga Mbolla, B.F. (2020) What Strategy for a Severe Stroke in Africa: Palliative Care or Unreasonable Obstinacy? World Journal of Neuroscience, 10, 37-41.

https://doi.org/10.4236/wjns.2020.101006

Received: June 24, 2019

Accepted: February 7, 2020

Published: February 10, 2020

Copyright $\odot 2020$ by author(s) and Scientific Research Publishing Inc. This work is licensed under the Creative Commons Attribution International License (CC BY 4.0).

http://creativecommons.org/licenses/by/4.0/

\begin{abstract}
Introduction: Palliative care, firstly used for chronic diseases, is currently indicated for some acute pathology such as Stroke. Its implementation improves the quality of care for end-of-life patients. The aim of our study is to report a series of patients who died in the intensive care stroke unit of Brazzaville. Method: It was a descriptive study of a series of 13 cases of severe stroke, admitted to the intensive care unit of the university hospital of Brazzaville, between January 2015 and December 2017. Sociodemographic, clinical, paraclinical and prognostic variables were studied. Result: The mean age of the patients was $46 \pm 11.5$ years with a male predominance in $69.2 \%$ ( $\mathrm{n}=$ 9). They were all hypertensive. The motor deficit and consciousness disorder association was the reason for admission in $84.6 \%(\mathrm{n}=11)$ and an epileptic seizure of $15.4 \%(\mathrm{n}=2)$. The mean NIHSS at admission was $21 \pm 5$, that of Glasgow $6 \pm 3$. Stroke was hemorrhagic in $84.6 \%(\mathrm{n}=11)$ and malignant infarction in $15.4 \%(n=2)$. All of these patients received invasive resuscitation with assisted ventilation and all died within 8 days of admission. Conclusion: The issue of limitation of care deserves to be debated, and is proposed on a case-by-case basis, in the face of a serious stroke. Therapeutic relentlessness is not only expensive, but also raises the problem of suffering of the individual at the end of life.
\end{abstract}

\section{Keywords}

Severe Stroke, Palliative Care, Stroke Unit, Africa

\section{Introduction}

Severe stroke is characterized by the combination of initial clinical severity, as- 
sessed by the NIHSS and the volume of brain injury [1] [2]. Studies on palliative care in the acute phase of a stroke are increasingly reported [3] [4]. It is more and more recognized as a crucial part of modern stroke care [1] [3] [5]. But no study specifies the exact profile of patients requiring palliative care in the acute phase, which sometimes makes it difficult to decide on limiting therapies to any patient [1] [6]. The American Stroke Association and the American Heart Association published a policy statement on the importance of integrating palliative care in patients diagnosed with cardiovascular and cerebrovascular disease, but there is no specific description of how to do, or which patients could benefit most from palliative care [7]. In Africa, the sacredness of life, demands that it must be extended by all means. Thus, no family gives its agreement for a limitation of therapeutics, which appears as abandonment. This situation most often favors recourse to unreasonable obstinacy.

The aim of our report is to present the evolution of a series of severe stroke cases that have been invasively resuscitated.

\section{Patients and Method}

It was an observational, descriptive study of a series of 13 cases of severe stroke, admitted to intensive care unit of university hospital of Brazzaville, between January 2015 and December 2017. The inclusion criteria were stroke patients with NIHSS $\geq 17$ and/or Glasgow scale $\leq 10$ at admission. Patients with heart failure at admission were excluded. Sociodemographic, clinical, paraclinical and prognostic variables were studied. We obtained informed consent from patient families.

\section{Results}

The mean age of the patients was $46 \pm 11.5$ years with a male predominance in $69.2 \%(\mathrm{n}=9)$. The different vascular risk factors are shown in Table 1 . The distribution by professional status is shown in Figure 1. The motor deficit and consciousness disorder association was the reason for admission in $84.6 \%(\mathrm{n}=$ $11)$ and an epileptic seizure of $15.4 \%(\mathrm{n}=2)$. The mean NIHSS score at admission was $21 \pm 5$ (extremes: 17 - 32), that of Glasgow $6 \pm 3$ (extremes: 3 - 10). Stroke was hemorrhagic in $84.6 \%(\mathrm{n}=11)$ and malignant infarction in $15.4 \%(\mathrm{n}$ $=2$ ). The mean systolic blood pressure was $201 \pm 42 \mathrm{~mm} \mathrm{Hg}$, the mean diastolic blood pressure was $145 \pm 38 \mathrm{~mm} \mathrm{Hg}$ : All of these patients, in agreement with their family, received invasive resuscitation with assisted ventilation and all died within 8 days of admission. Figure 2 shows the cerebral CT-Scan of a 38-year-old patient admitted for right hemiplegia and loss of consciousness, with systolic blood pressure of $240 \mathrm{~mm} \mathrm{Hg}$. Despite the invasive treatment, he died on the $6^{\text {th }}$ day.

\section{Discussion}

The implementation of palliative needs collaboration between patient, family 
Table 1. Different risk factors.

\begin{tabular}{ccc}
\hline & n & $\%$ \\
\hline High blood pressure & 13 & 100 \\
History of stroke & 02 & 15.4 \\
Diabetes & 01 & 07.7 \\
Smoking & $/$ & $/$ \\
Alcohol intake & 07 & 53.8 \\
\hline
\end{tabular}

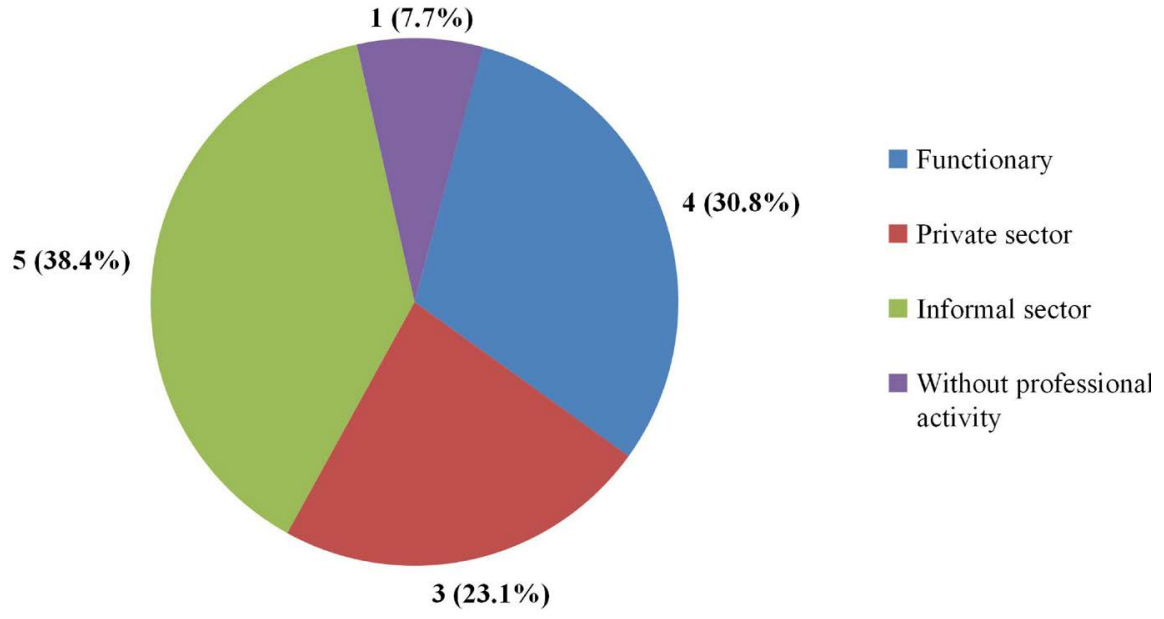

Figure 1. Distribution par professional status.

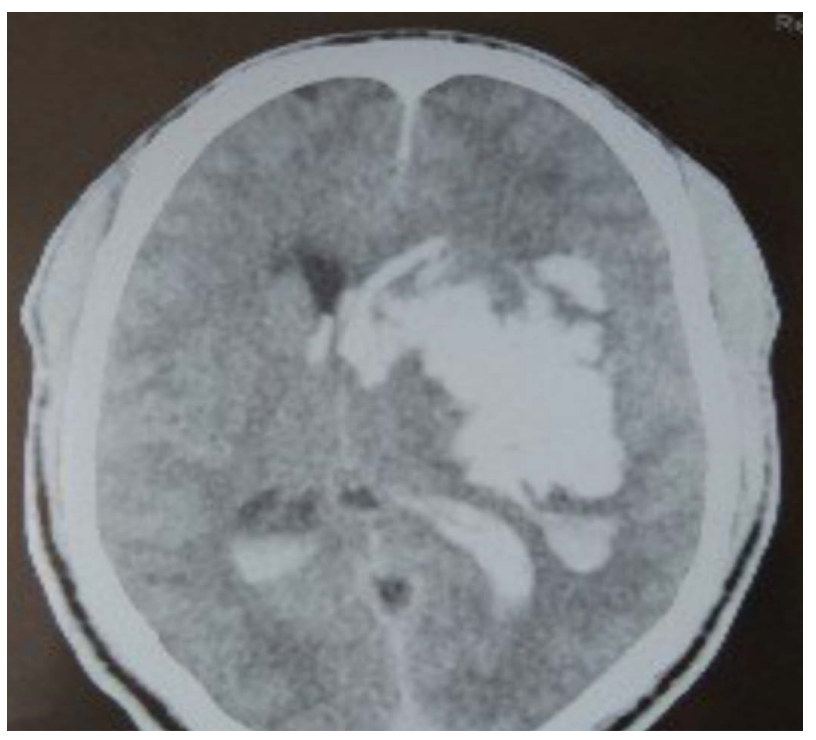

Figure 2. Cerebral CT-scan showing a large, deep hematoma, with mass effect, falcocoral involvement and ventricular flood.

and an interdisciplinary team who develops, implements, and updates the care plan to anticipate, prevent, and treat physical, psychological, social and spirituals needs. It ensures that all patients and families have access to treatments that are evidence-based and provided in accordance with their values, assessed needs, 
and goal of care [4] [8]. In Africa, the absence of multidisciplinary palliative care teams on the one hand, and socio-cultural considerations on the other, most often explain the use of unreasonable obstinacy and invasive care in end-of-life subjects. In our series, the main motivation for invasive care was the young age of the patients. It demonstrates that early involvement of palliative care prompted earlier family meetings, quality of communication and a trend toward decreased hospital length of stay and death [9] [10]. In our report, all patients had the history of arterial hypertension and elevated blood pressure at admission. It is recognized that the history of hypertension and elevation of blood pressure in the acute stroke are common and associated with poor prognosis, especially in cases of intracerebral hemorrhage [11] [12]. The high frequency of intracerebral hemorrhage in patients eligible for palliative care in our series was also reported by Williams et al. [4]. This is because mortality is higher in case of intracerebral hemorrhage. It is estimated that one in three patients die within the first month of onset [13]. Clinically, the onset of impaired awareness on admission, a high NIHSS $(>20)$ and the Glasgow low score $(<6)$ should involve the palliative care team and families, to decide the most appropriate therapeutic decision. All our cases were intubated. The literature data suggest that patients with stroke who are intubated have a high 30-day mortality rate, and need palliative care [4] [14]. The reflection on palliative care in intensive care should be conducted in Africa, because in most of these countries, there is no social security, care is the exclusive responsibility of patients and their families. The use of inadequate care is a source of psychological and financial suffering for the family.

\section{Conclusion}

The issue of limitation of care deserves to be debated, and is proposed on a case-by-case basis, in the face of a severe stroke. The use of palliative care in intensive care is poorly reported in Africa. However, in the absence of social security systems, unreasonable obstinacy is for the patient and his entourage, a source of suffering, not only psychological, but also financial. A reflection should be leaded or even legislation for the care of patients at the end-of-life.

\section{Conflicts of Interest}

The authors declare no conflicts of interest regarding the publication of this paper.

\section{References}

[1] Alonso, A., Ebert, A.D., Dörr, D., et al. (2016) End-of-Life Decisions in Acute Stroke Patients: An Observational Cohort Study. BMC Palliative Care, 15, 38. https://doi.org/10.1186/s12904-016-0113-8

[2] Mihindu, E., Mohammed, A., Smith, T., et al. (2019) Patients with Moderate to Severe Strokes (NIHSS Score > 10) Undergoing Urgent Carotid Interventions within 48 Hours Have Worse Functional Outcomes. Journal of Vascular Surgery, S0741-5214(18)32230-4. https://doi.org/10.1016/j.jvs.2018.07.079 
[3] Molidor, S., Overbaugh, K.J., James, D., et al. (2018) Palliative Care and Stroke: An Integrative Review of Literature. Journal of Hospice \& Palliative Nursing, 20, 358-367. https://doi.org/10.1097/NJH.0000000000000450

[4] Williams, M.T., Zimmerman, E., Barry, M., et al. (2019) A Retrospective Review of Patients with Acute Stroke and without Palliative Care Consultations. The American Journal of Hospice \& Palliative Care, 36, 60-64. https://doi.org/10.1177/1049909118787136

[5] Tran, L.N., Back, A.L. and Creutzfeldt, C.J. (2016) Palliative Care Consultations in the Neuro-ICU. A Qualitative Study. Neurocritical Care, 25, 266-272. https://doi.org/10.1007/s12028-016-0283-5

[6] Creutzfeldt, C.J., Holloway, R.G. and Curtis, J.R. (2015) Palliative Care: A Core Competency for stroke Neurologists. Stroke, 46, 2714-2719.

https://doi.org/10.1161/STROKEAHA.115.008224

[7] Braun, L.T., Grady, K.L., Kutner, J.S., et al. (2016) American Heart Association Advocacy Coordinating Committee. Palliative Care and Cardiovascular Disease and Stroke: A Policy Statement from the American Heart Association/American Stroke Association. Circulation, 134, e1-e28. https://doi.org/10.1161/CIR.0000000000000438

[8] Ferrell, B.R., Twaddle, M.L., Melnick, A., et al. (2018) National Consensus Project Clinical Practice Guidelines for Quality Palliative Care Guidelines, 4th Edition. National Coalition for Hospice and Palliative Care, Richmond, VA. https://doi.org/10.1089/jpm.2018.0431

[9] Nelson, J.E., Puntillo, K.A., Pronovost, P.J., et al. (2010) In Their Own Words: Patients and Families Define High-Quality Palliative Care in the Intensive Care Unit. Critical Care Medicine, 38, 808-818. https://doi.org/10.1097/CCM.0b013e3181c5887c

[10] Braus, N., Campbell, T.C., Kwekkeboom, K.L., et al. (2016) Prospective Study of a Proactive Palliative Care Rounding Intervention in a Medical ICU. Intensive Care Medicine, 42, 54-62. https://doi.org/10.1007/s00134-015-4098-1

[11] Gombet, T.R., Ossou-Nguiet, P.M., Ellenga-Mbolla, B.F., et al. (2013) Hypertension and Intracerebral Hemorrhage in Brazzaville. World Journal of Cardiovascular Disease, 3, 523-528. https://doi.org/10.4236/wjcd.2013.39083

[12] Ossou-Nguiet, P.M., Gombet, T., OssilAmpion, M., et al. (2013) Mortality Factors for Stroke at Brazzaville University Hospital. Revue Africaine d'Anesthésie et de Médecine d'Urgence, 18, 15-19.

[13] Cordonnier, C., Demchuk, A., Ziai, W., et al. (2018) Intracerebral Haemorrhage: Current Approaches to Acute Management. Lancet, 392, 1257-1268. https://doi.org/10.1016/S0140-6736(18)31878-6

[14] Holloway, R.G., Benesch, C.G., Burgin, W.S., et al. (2005) Prognosis and Decision Making in Severe Stroke. JAMA, 294, 725-733.

https://doi.org/10.1001/jama.294.6.725 